\title{
Riski Seven ve Riskten Kaçan Yatırımcıların Optimum Portföy Seçimi Yapabilecekleri Piyasalar ${ }^{1}$
}

\section{Markets in Which Investors Who Are Risk-Loving and Escaping From Risk Can Make Optimum Portfolio Selection}

Öğr. Gör. Recep ÇAKAR ${ }^{2}$ - Araş. Gör. Oktay ÖZKAN

\author{
Başvuru Tarihi: 06.07.2018 \\ Kabul Tarihi: 23.12.2019 \\ Makale Türü: Araştırma Makalesi
}

Öz

Çalışmanın amacı, riski seven ve riskten kaçan yatırımcı tiplerini, optimum portföy oluşturabilecekleri pazarlara yönlendirmektir. Ayrıca bu iki yatırımcı tipi için en uygun piyasaların hangileri olduğu tespiti de yapılacaktır. Bu amaçla çalışmada, 2017 Dünya Bankası verilerine göre gelişmiş ve gelişmekte olan 20 ülkenin piyasalarını temsil eden pazar endekslerinin 2010-2017 yılları arasındaki aylık getiri verileri kullanılmıştır. Pazar endekslerinin verileri kullanılarak Kuadratik Ortalama-Varyans Modeli ile optimum portföyler oluşturulmuş ve her bir pazar endeksinin değişim katsayısı hesaplanmıştır. Gelişmiş ve gelişmekte olan ülke piyasalarının endeks bazında riskleri de hesaplanarak, hangi endekslerin hangi yatırımcı tipleri için rasyonel olacağı tespit edilmiştir. Gerçekleştirilen analiz sonuçlarına göre, riski seven yatırımcı tipileri için optimum portföyler Venezuela, Tayland, Meksika, Malezya, Kosta Rika, Arjantin ve Güney Afrika pazar endekslerinde oluşturabileceği ve aynı zamanda bu yatırımcılar için endeks bazında en riskli olan piyasaların Venezuela, Arjantin ve Kazakistan olduğu anlaşılmıştır. Riskten kaçan yatırımcıların optimum portföylerini İzlanda, ABD ve Norveç endeksleriyle oluşturabileceği ve aynı zamanda bu yatırımcılar için endeks bazında en risksiz olan piyasaların İniltere, İsviçre ve Kanada olduğu sonuçlarına ulaşılmıştır.

Anahtar Kelimeler: Optimum Portföy, Riski Seven Yatırımcı, Riskten Kaçan Yatırımcı

\footnotetext{
${ }^{1}$ Bu çalışma 08-10 Nisan 2017 tarihleri arasında İktisadi Kalkınma ve Sosyal Araştırmalar Derneği (IKSAD) tarafından Batum-Gürcistan'da düzenlenen 1. Uluslararası Mesleki ve Teknik Bilimler Kongresi’nde sözlü olarak sunulmuştur.

2 Hitit Üniversitesi SBMYO Finans Bankacllk ve Sigortacllı Bölümü, recepcakar@hitit.edu.tr, ORCID: 0000-0002-4069-7653

${ }^{3}$ Tokat Gaziosmanpaşa Üniversitesi İİB İşletme, oktay.ozkan@gop.edu.tr, ORCID ID: 0000-0001-9419-8115
} 


\begin{abstract}
The aim of the work is to direct the investor types who are risk-loving and risk-averse to the markets in which they can create optimum portfolios. It will also be possible to determine the most suitable markets for these two types of investors. For this purpose, monthly returns between 20102017 of market indexes representing the markets of developed and developing 20 countries according to World Bank data of 2017 were used. Using the data of the market indices, optimal portfolios are constructed with the Quadratic Mean-Variance Model and the coefficient of variation of each market index is calculated. By calculating the index-based risks of developed and developing country markets, it was determined which indices would be rational for which investor types. According to the results of the analysis, it is understood that the most risky markets for Venezuela, Thailand, Mexico, Malaysia, Costa Rica, Argentina and South Africa market indexes for these risk-loving investor types are Venezuela, Argentina and Kazakhstan. It is concluded that investors who have run away from the risk can create optimal portfolios with Icelandic, US and Norwegian indices, while at the same time these markets are Britain, Switzerland and Canada, which are the least risky indices for these investors.
\end{abstract}

Keywords: Optimum Portfolio, Risk-Loving Investor, Risk-Averse Investor

\title{
Giriş
}

Bir ülkedeki küçük büyük bütün tasarrufların sermaye piyasalarına kanalize edilmesi ekonomik gelişim ve istikrar için en çok arzu edilen durumdur. Fakat sermaye piyasalarına her geçen gün yeni finansal araçların girmesi, risk ve getiri hesaplamalarını önemli ölçüde değiştirmektedir. Sürekli gelişen bu ortamda yatırımcıların rasyonel davranması zorlaşmakta, tecrübe ve bilgi ihtiyacı artmaktadır. Bu bilgiler ışığında özellikle küçük yatırımcıların yapacağı işlemler büyük riskler taşımaya başlamıştır. Yatırımcıların karşı karşıya olduğu bu risklerin optimum hale getirilmesi ve tasarrufların finansal araçlar arasında minimum risk-maksimum getiri sağlayacak şekilde yönetilmesi portföy yönetimi kavramını ifade etmektedir (Ceylan vd. 2004, s. 423; Akman, 2011, s. 54).

$\mathrm{Bu}$ çalışmanın amacı, riski seven ve riskten kaçan yatırımcı tiplerini, optimum portföy oluşturabilecekleri pazarlara yönlendirmektir. Bu bağlamda çalışmamızda riski seven yatırımcılar için gelişmekte olan ülke piyasalarının risk getiri düzeyleri ve riskten kaçan yatırımcılar içinde risk algısı düşük olan gelişmiş ülke piyasalarının beklenen getiri ve risk düzeyleri analiz edilecektir. Çalışmada Dünya bankası verilerine göre gelişmiş ve gelişmekte olan toplam 40 ülkenin pazar endeks verileri kullanılmıştır. Veri seti içindeki ülkelerin Pazar endeks değerleriyle beklenen getiri ve riskleri hesaplanmıştır. Ayrıca bulunan beklenen getiri ve risk verilerine göre Ortalama-Varyans yöntemine göre Kuadratik Programlamaya tabi tutularak optimum portföyler oluşturulmuştur. Optimum portföyler Sharpe oranı kullanılarak oluşturulmuştur. Ayrıca ülke endekslerinin risk sıralaması yapılmıştır. 
Riski seven ve riskten kaçan yatırımcılar için riskli ve risksiz piyasalarda optimum (belli bir getiri düzeyinde en düşük risk taşıyan yada belli bir risk düzeyinde en yüksek getiri imkanı olan) portföy oluşturabilecekleri ülkeler belirlenmiştir. Yatırımcıların optimum portföyler oluşturmaları için tarafımızca oluşturulan portföylerdeki ülke ağırlıklarına göre portföylerini çeşitlendirmeleri fayda düzeylerini maksimum yapacağı söylenebilir. Portföy optimizasyonu konusundaki literatür incelendiğinde, çalışmaların büyük bir çoğunluğu yatırımcı tipi ayrımı gözetmeksizin, yatırımcı tipi dikkate alınan az sayıda çalışmalarda da belirli endekslerde karmalar yapılmak suretiyle optimum portföy oluşturulması üzerine yapılmıştır. Çalışmamızı literatürdeki çalışmalardan farklı kılan nokta çalışmamızın yatırımcı tipleri açısından piyasaları ele alarak gelişmiş ve gelişmekte olan ülkelerden oluşan 40 farklı ülkenin pazar endeksine dayalı uluslararası çeşitlendirme yapmak isteyen yatırımcıları (riski seven ve riskten kaçan) daha yüksek getiri daha düşük risk içeren piyasalara yönlendirmesidir. Bu noktada literatüre katkı yapacağı ve yatırımcılar için portföy planlaması aşamasında faydalı olacağı düşünülmektedir.

\section{Kavramsal Çerçeve}

Gerçekleşen getirinin beklenen getiriden farkı finans dilinde risk olarak adlandırılır. Finansal varlıkların beklenen getiri ve risklerinin hesaplanması için çeşitli modeller geliştirilmiştir. Finansal varlıkların riskleri sistematik ve sistematik olamayan riskler olarak tanımlanmıştır. Portföy yönetimi konusunda Markowitz'in Ortalama-Varyans Modeli bilinen en optimum modeldir (Francis, 1991, s.239). Ortalama-Varyans Modeline göre portföyün getirisi portföyü oluşturan varlıkların beklenen getirilerinin ağırlıklı ortalamalarından oluşurken, portföyün riski finansal araçların riskinin ağırlıklı ortalamalarının toplamını ifade etmemektedir. Markowitz'e göre aynı risk düzeyinde en yüksek getiriyi veya belirli bir getiri düzeyinde en düşük riski veren optimum portföyler oluşturulabilir (Aygören ve Akyer, 2013, s.9; Çetin, 2007, s.64). Markowitz’in önerdiği modelle birlikte geleneksel portföy anlayışına göre yalın çeşitlendirme yoluyla riskin azaltılabileceği anlayışı yerini portföye dahil edilecek finansal araçlar arasındaki korelasyon ilişkisi ile riskin düşürüleceği anlayışına bırakmıştır (Keskintürk, 2007, s.79; Tosun ve Oruç, 2010, s.480).

Yatırımcılar, yatırımlarını risk ve beklenen getiri tahminlerine göre yaparlar ve her bir yatırımcının risk ve getiri profili farklılık arz eder. Her yatırımcı tipi için alternatif portföylere bir fayda değeri verilebileceği varsayımı altında yatırımcı tipleri için fayda fonksiyonu oluşturulabilir. Fayda fonksiyonu alternatif portföylerin risk ve getiri durumuna göre belirlenir. Böylece yatırımcı açısından portföyler iyiden kötüye doğru sıralanmış olacaktır. Yatırımcı bulunduğu risk grubunda, karşılaştığı daha uygun risk getiri grubuna daha yüksek fayda değeri verecektir. Portföylerin daha fazla fayda değeri için daha düşük risk ya da daha yüksek beklenen getiri profiline sahip olması gerekecektir. Bu bilgiler ışığında oluşturulan fayda fonksiyonu, yatırımcının risk grubu, yatırımdan beklenen getiri ve varyans değişkenleri kullanılarak aşağıdaki formül yardımıyla hesaplanabilir (Korkmaz vd. 2013, s.16-18).

$$
\mathrm{F}=\mathrm{E}(\mathrm{R})-0,005 * \mathrm{~A} * \sigma^{2}
$$


Formülde yer alan,

$\mathrm{F}=$ Fayday1,

$\mathrm{E}(\mathrm{R})=$ Beklenen getiriyi,

A = Yatırımcının riskten kaçınma derecesini,

$\sigma=$ Standart sapma değerini,

ifade etmektedir.

Kurulan fonksiyonda ifade edildiği gibi beklenen getirideki artı̧̧ faydayı artırmakta, riskteki artış faydayı düşürmekte ve en önemlisi müşterinin risk grubu faydayı doğrudan etkilemektedir. Risk derecesinin faydayı ne kadar düşürdüğü yatırımcının riskten kaçınma derecesiyle (A) belirlenmektedir. Fonksiyondaki yatırımcının riskten kaçınma derecesi arttığında yatırımcının riskten kaçan yatırımcı olduğunu tersi durumda riski seven yatırımcı olduğunu ifade eder (Kaya ve Kocadağlı, 2012, s.22). Alternatif portföyler arasında tercih yapacak olan yatırımcı kendisine en yüksek fayda değerini veren portföy karmasını tercih edecektir.

Yatırımcı tiplerinden riskten kaçan yatırımcılar; riski sevmedikleri için getirisi belli olan iki yatırım alternatifinden daha az riskli olanı tercih ederler. Ayrıca bu yatırımcı tipleri riski en düşük olan piyasalarda portföy karmasını oluştururlar. Riske karşı kayıtsız yatırımcılar; riskle ilgili değillerdir, bu tür yatırımcılar için ' $A=0$ ' olarak alınır ve sadece beklenen getiriye göre yatırım yaparlar. Riski seven yatırımcı tipi için yatırımın risk primi sıfır ya da sıfırın altındadır, ayrıca risk almak için ayrıca ek risk primi talep etmezler (Korkmaz vd. 2013, s.16-18).

Yatırımcı tiplerinden de beklenen, bulundukları risk grubuna uygun olan piyasalarda yatırım yapmak olacaktır. Yatırımcı tipleri için gelişmiş ve gelişmekte olan ülke piyasaları da risksiz ve riskli piyasalar olarak sınıflandırılabilmektedir. Gelişmekte olan ülkelerde büyüme ve risk beklentisi gelişmiş ülkelere göre daha fazladır. Yatırımcı, istikrar ortamında daha fazla getiri beklentisi olan ülke piyasalarında yatırım yaparak yüksek getiriye ulaşmak ister, riskli durumlarda ise düşük riskli piyasalara yönelir. Yatırımcı tipleri açısından değerlendirildiğinde ise yatırımcılar finans bilimi açısından; riski seven, riskten kaçan ve riske karşı kayıtsız olarak üç kısımda ele alınır (Kaderli ve Akbulut, 2009, s.216). Riski seven yatırımcılar genellikle beklenen getiri algisı yüksek olan gelişmekte olan ülkelere yönelecek, riskten kaçan yatırımcılarda genellikle riski düşük gelişmiş ülke piyasalarına yönelecektir (Ayaydın, 2014, s.44).

\section{Literatür Özeti}

İlgili literatür çalışmalarına ilişkin bazı örnekler aşağıda yer almakta olup, çalışmalar ağırlıklı olarak yatırımcı tipi bağlamında ele alınmamış optimum portföy oluşturulmasına yönelik gerçekleştirilmiştir.

Kardiyen (2008) çalışmasında Markowitz'in ortalama varyans modeli ile ortalama mutlak sapma modelini karşılaştırmıştır. Ortalama varyans modelinin risk getiri dengesi açısından varlıkları, birbirleriyle olan ilişkilerini ortaya koyan ve portrföyün tümünü değerlendirerek çeşitlendirmeye imkan veren bir model olarak tanınmamış günümüzde de hala kullanılmakta 
olduğunu vurgulamıştır. Çalışmasında ortalama varyas modeli ile Konno ve Yamazaki tarafından önerilen MAD Modelidini BİST50 Endeksi üzerinde bir simülasyonla karşılaştırılmıştır. Çalışma sonucunda ortalama varyans modeli ve MAD modeli getirileri genelde birbirleri ile aynı ya da çok yakın olduğu sonucuna varmış, ortalama varyans modeli ile elde edilen portföylerin riskinin MAD modelinden nispeten daha düşük olduğunu vurgulamıştır.

Demirtaş ve Güngör (2004) çalışmalarında BİST30 endeksi üzerinde yaptığı modellemeler de ortalama varyans modelini kullanmış ve yatırımcılara ve Portföy yöneticilerine rasyonel tercihte bulunabilecekleri sonuçların çıktığına vurgu yapmıştır.

Küçükkocaoğlu (2002) çalışmasında İMKB'de işlem gören 283 şirketin 2001 yılı itibariyle verilerini kullanarak ortalama varyans modeline göre yaptığı analizde kurumsal ve bireysel yatırımcı tipleri için İMKB100 ve İMKB30 endeksinde uygun optimal portföylerine olabileceği sonucuna varmıştır.

Akçayır vd. (2014) çalışmalarında Tek indeks modeli ve ortalama varyans modelinin uygulanabilirliği üzerine İMKB30'daki hisse senetlerini kullanarak çeşitli portföyler oluşturmuştur. Çalışma sonuçlarına göre Tek indeks modeline göre oluşturulan portföylerin risk getiri oranlarının ortalama varyans modeline uyarlandığında getiri düzeyi yüksek ve düşük yeni portföyler oluşturabileceği sonucuna varmıştır.

Boztosun vd. (2005) çalışmalarında İMKB100 endeksinde bulunan hisse senetlerini kullanarak ortalama varyans modeli ile çeşitli portföyler oluşturmayı denemiştir. Hisselerin 15 günlük, aylık ve 3 aylık getirileri kullanılarak çeşitli kovaryans matrisleri oluşturmuş ve modellemeler çözümlenmiştir. Çalışma sonucuna göre yatırımcı davranışları doğrultusunda İMKB100 endeksinde daha istikrarlı portföyler oluşturmak için daha fazla risk almak zorunda olunduğu belirtilmiştir.

Abay (2013) Çalışmasında portföy seçimi ve risk yönetimi süreçlerinin karmaşıklığına vurgu yaparak İMKB30 endeksindeki hisse senetlerini kullanarak ortalama varyans yöntemi ile çeşitli portföyler oluşturmuştur. Oluşturduğu portföylerin yatırımcılara risk getiri dengesi açısından çeşitli senaryolar ile karar vermelerine yardımcı olacağı vurgulanmıştır.

\section{Yöntem}

Riski seven yatırımcılar için gelişmekte olan piyasalarda, riskten kaçan yatırımcı tipleri için gelişmiş piyasalarda fayda değeri en yüksek olan portföyler oluşturmak amaçlanmıştır. Bu amaçla hangi ülke piyasa karmalarıyla optimum portföyler kurulacağı Ortalama-Varyans Modeli Kuadratik Programlama yöntemiyle tespit edilecektir (Atan vd. 2018, s.26-27). Portföy optimizasyonu Sharpe katsayısını maksimum yapan portföy karmalarından oluşturulacaktır. Ayrıca riskten kaçan ve riski seven yatırımcılar için endeksler risklerine göre sıralanacaktır. $\mathrm{Bu}$ amaçla Dünya Bankası verilerine göre gelişmekte olan 20 ülkenin piyasaları ve gelişmiş 20 ülkenin piyasalarını temsil eden pazar endekslerinin 2010-2017 yılı aylık getiri verileri kullanılacaktır. Optimum portföyler oluşturmak ve risk hesaplamaları için kullanılacak yöntemler aşağıda tanıtılmıştır. 
Markowitz, (1952); menkul kıymetler arasında düşük kovaryansa sahip olanlarının portföye dahil edilmesi suretiyle, yatırımcıların hem beklenen getirilerini maksimize etmelerini hem de yatırımlarının risklerinin minimize etmelerini sağlayacak portföye ulaşmaları mümkün olmaktadır. Ayrıca etkin beklenen getiri-varyans kombinasyonları sağlayan portföylerin belirlenebilmesini sağlayan linear kısıtlar altında kuadratik bir fonksiyon geliştirmiştir.

Markowitz tarafından geliştirilen kuadratik programlamanın uygulanışı aşağıdaki gibidir.

$$
\begin{aligned}
\mathrm{W}^{\mathrm{T}} & =\left[\begin{array}{c}
\mathrm{W}_{1} \\
\mathrm{~W}_{2} \\
\mathrm{~W}_{3} \\
\cdot \\
\mathrm{W}_{\mathrm{n}}
\end{array}\right]: \text { Portföy içerisindeki varlıkların ağırlık vektörü } \\
\mathrm{ER}^{\mathrm{T}} & =\left[\begin{array}{c}
\mathrm{ER}_{1} \\
\mathrm{ER}_{2} \\
\mathrm{ER}_{3} \\
\cdot \\
\mathrm{ER}_{\mathrm{n}}
\end{array}\right]: \text { Portföy içerisindeki varlıkların beklenen getiri vektörü }
\end{aligned}
$$

Ortalama-Varyans Modeli’ne göre bir portföyün beklenen getirisi aşağıdaki formül kullanılarak hesaplanmaktadir:

$$
\mathrm{ER}_{\mathrm{P}}=\sum_{\mathrm{i}=1}^{\mathrm{n}} \mathrm{ER}_{\mathrm{i}} * \mathrm{~W}_{\mathrm{i}}
$$

Formülde yer alan;

$\mathrm{ER}_{\mathrm{P}}$ : Portföyün beklenen getirisini,

$\mathrm{ER}_{\mathrm{i}}$ : i'inci menkul klymetin beklenen getirisini,

$\mathrm{W}_{\mathrm{i}}$ : i’inci menkul kıymetin portföy içerisindeki ağırlığını,

ifade etmektedir.

Yukarıda yer alan formülün Kuadratik Programlama içerisindeki gösterimi aşağıdaki gibidir:

$$
\begin{aligned}
& \mathrm{ER}_{\mathrm{P}}=\mathrm{ER}^{\mathrm{T}} \mathrm{W}^{\mathrm{T}}=\left[\begin{array}{c}
\mathrm{ER}_{1} \\
\mathrm{ER}_{2} \\
\mathrm{ER}_{3} \\
\cdot \\
\mathrm{ER}_{\mathrm{n}}
\end{array}\right]\left[\begin{array}{c}
\mathrm{W}_{1} \\
\mathrm{~W}_{2} \\
\mathrm{~W}_{3} \\
\cdot \\
\mathrm{W}_{\mathrm{n}}
\end{array}\right]
\end{aligned}
$$

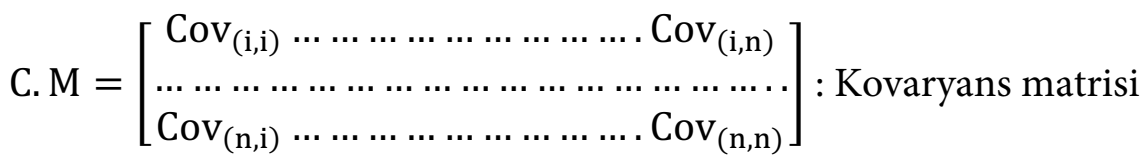

Matriste yer alan Cov, menkul kıymetler arasındaki kovaryans katsayısını göstermektedir. 
Ortalama-Varyans Modeli’ne göre bir portföyün varyansı ve standart sapması aşağıdaki formüller kullanılarak hesaplanmaktadır:

$$
\begin{aligned}
& \sigma_{\mathrm{p}}^{2}=\sum_{\mathrm{i}=1}^{\mathrm{n}} \sum_{\mathrm{j}=1}^{\mathrm{n}} \mathrm{W}_{\mathrm{i}} * \mathrm{~W}_{\mathrm{j}} * \sigma_{\mathrm{i}} * \sigma_{\mathrm{j}} * \mathrm{Kor}_{\mathrm{i}, \mathrm{j}} \\
& \sigma_{\mathrm{p}}=\sqrt{\sigma_{\mathrm{p}}^{2}} \\
& \operatorname{Kov}_{\mathrm{i}, \mathrm{j}}=\operatorname{Kor}_{\mathrm{i}, \mathrm{j}} * \sigma_{\mathrm{i}} * \sigma_{\mathrm{j}}
\end{aligned}
$$

Formüllerde yer alan;

$\sigma_{\mathrm{p}}^{2}$ : Portföyün varyansını,

$\sigma_{\mathrm{p}}:$ Portföyün standart sapmasını,

$\mathrm{W}_{\mathrm{i}}$ : i’inci menkul kıymetin portföy içerisindeki ağırlığını,

$\mathrm{W}_{\mathrm{j}}$ : j’inci menkul kıymetin portföy içerisindeki ağırlığını,

$\sigma_{\mathrm{i}}$ : i’inci menkul kıymetin standart sapmasını,

$\sigma_{\mathrm{j}}:$ j’inci menkul kıymetin standart sapmasını,

Kor $_{\mathrm{i}, \mathrm{j}}$ : i’inci ve j’inci menkul kıymetler arasındaki korelasyon katsayısını,

$\operatorname{Kov}_{i, j}$ : i’inci ve j'inci menkul kıymetler arasındaki kovaryans katsayısını,

ifade etmektedir.

Yukarıda yer alan formülün Kuadratik Programlama içerisindeki gösterimi aşağıdaki gibidir:

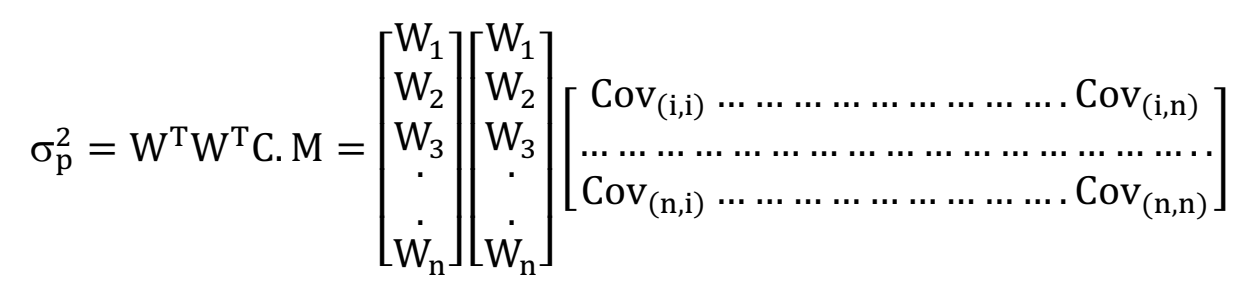

Kuadratik programlama içerisinde yer alan kısıtlamalar ise aşağıdaki gibidir:

$$
\begin{aligned}
& \min \sigma_{p}^{2}=\mathrm{W}^{\mathrm{T}} \mathrm{W}^{\mathrm{T}} \mathrm{C} . \mathrm{M}=\sum_{\mathrm{i}=1}^{\mathrm{n}} \sum_{\mathrm{j}=1}^{\mathrm{n}} \mathrm{W}_{\mathrm{i}} \mathrm{W}_{\mathrm{j}} \sigma_{\mathrm{i}, \mathrm{j}} \\
& \sum_{\mathrm{i}=1}^{\mathrm{n}} \mathrm{W}_{\mathrm{i}} \mathrm{ER}_{\mathrm{i}} \geq \mathrm{ER}_{\mathrm{t}} \\
& \sum_{\mathrm{i}=1}^{\mathrm{n}} \mathrm{W}_{\mathrm{i}}=1, \quad \mathrm{~W}_{\mathrm{i}} \geq 0 \quad \text { ve } \mathrm{i}=1,2,3, \ldots \ldots \ldots \ldots \mathrm{n}
\end{aligned}
$$

Kısıtlama içerisinde yer alan;

$\mathrm{ER}_{\mathrm{t}}$ : Hedeflenen beklenen getiri düzeyini,

$\mathrm{ER}_{\mathrm{i}}$ : i'inci menkul klymetin beklenen getirisini,

$\mathrm{W}_{\mathrm{i}}$ : i’inci menkul kıymetin portföy içerisindeki ağırlığını, 
$\mathrm{W}_{\mathrm{j}}$ : j’inci menkul kıymetin portföy içerisindeki ağırlığını,

$\mathrm{n}$ : Portföy içerisinde yer alan toplam menkul kıymet sayısını,

$\sigma_{i, j}$ : i’inci ve j'inci menkul kıymetler arasındaki kovaryans katsayısını,

$\sigma_{\mathrm{p}}^{2}$ : Portföyün varyansını,

$\mathrm{W}^{\mathrm{T}}$ : Portföy içerisindeki varlıkların ağırlık vektörünü,

C. M : Kovaryans matrisini,

ifade etmektedir.

Sharpe endeksinin değeri, portföyün beklenen değeri ve risksiz faiz oranı arasındaki fark olarak tanımlanan risk priminin portföyün standart sapmasına bölünmesi ile elde edilmektedir. Sharpe oranı, en yaygın ve basit kullanımı olan riske göre düzeltilmiş performans ölçme tekniklerinden birisi olarak tanımlanabilir (Sharpe, 1963, s.281-284; Redman vd. 2005, s.76).

$$
S=\frac{r_{p}-r_{f}}{\sigma_{p}}
$$

$r_{p}:$ Portföyün getirisi

$\mathrm{r}_{\mathrm{f}}$ : Risksiz Faiz Oranı

$\sigma_{\mathrm{p}}:$ Portföyün Standart Sapması

Sharpe katsayısı portföyün bir birimlik risk karşısında ne kadarlık getiri elde edebileceğini ifade eder. Ayrıca kuadratik programlama ile en yüksek Sharpe değeri istenerek portföy oluşturulursa, bu portföy en verimli portföy karmasını ifade eder.

Değişim katsayısı; Portföy optimizasyonu için alternatif finansal araçlar arasında risk getiri ilişkisini dikkate alan bir başka ölçüttür. Değişim katsayısıyla her bir birim getiri elde etmek için katlanılan riskin seviyesini ifade eder. Kuadratik programlama kısıtlarına değişim katsayısını minimum yapan portföy karması oluştur komutu verildiğinde elde edilecek yeni bir optimum portföy ortaya çıkacaktır. Değişim katsayısı aşağıdaki formülde ifade edilmektedir (Korkmaz vd. 2013, s.16-18).

Değişim Katsayısı $=\frac{\sigma}{\mathrm{r}}$

Burada;

$\sigma=$ Standart sapmay 1

$\mathrm{r}=$ Getiri oranını göstermektedir. 


\section{Veri Seti}

Kişi başına düşen milli geliri 1.026 - 12.475 dolar aralığında olan ülkeler Dünya Bankası'na göre gelişmekte olan (Orta Gelir Ülkeleri) olarak tanımlanmaktadır. Kişi başına milli geliri 12.475 dolar üstünde olan ülkeler ise gelişmiş ülke kategorisinde değerlendirilir. Çalışmada gelişmiş ve gelişmekte olan toplam 40 ülkenin pazar endekslerine ait 01/01/2010-31/12/2017 tarihleri arasındaki aylık verileri analize tabi tutulmuştur (Dünya Bankası, http://www.worldbank.org/en/country /mic/overview: Erişim Tarihi: 01.02.2018). Veriler Investing isimli internet sitesinden elde edilmiştir (Erişim Tarihi: 01.02.2018).

\section{Bulgular}

Çalışma kapsamında; gelişmiş ve gelişmekte olan ülkelerin pazar endeks verileri kullanılarak Microsoft Excell 2010 Programı kullanılarak analizler gerçekleştirilmiştir. İlk olarak gelişmekte olan ve gelişmiş piyasalar Tablo 1 ve Tablo 2'de olduğu gibi risk düzeylerine göre büyükten küçüğe doğru sıralanmıştır. Aynı tablolarda ülke endekslerinin risk prim oranları ve değişim katsayısı verileri de yer almaktadır.

Ayrıca gelişmiş ve gelişmekte olan piyasalarda riski seven ve riskten kaçan yatırımcılar için optimum portföy karmaları Tablo 3 ve Tablo 4'te gösterilmiştir. Optimum portföyler, performans göstergesi olarak kabul edilen Sharpe Oranını maksimum yapan ağırlıklarla oluşturulmuştur.

Tablo 1'de gelişmekte olan ülke endeksleri taşıdıkları risklere göre en yüksek riskten en düşük risk düzeyine göre sıralanmıştır.

Tablo 1'de de görüldüğü gibi risk ölçütü olarak standart sapma değeri kullanılmıştır. Ülke endeksleri risk sıralamasında en yüksek risk taşıyan 3 ülke endeksi sırasıyla Venezuela Arjantin ve Kazakistan olduğu tespit edilmiştir. Ayrıca gelişmekte olan ülke endeksleri içinde en az riskli olanları sırasıyla Lübnan, Ürdün ve Bosna Hersek olduğu anlaşılmaktadır. 
Tablo 1. Gelişmekte Olan Ülkeler Risk Stralaması

\begin{tabular}{|c|c|c|c|c|c|}
\hline Pazar Endeksleri & Ortalama & Varyans & $\begin{array}{c}\text { Standart } \\
\text { Sapma } \\
\end{array}$ & Risk Primi & Değişim Katsayısı \\
\hline Bursatil (IBC) Venezuella & 0,09082 & 0,04162 & 0,20402 & 0,44515 & 2,24642 \\
\hline Merval (MERV)Arjantin & 0,03050 & 0,01033 & 0,10163 & 0,30010 & 3,33225 \\
\hline KASE (KASE)Kazakistan & 0,00013 & 0,00505 & 0,07109 & 0,00184 & 544,40476 \\
\hline $\begin{array}{l}\text { Shanghai Composite } \\
\text { (SSEC)Çin }\end{array}$ & 0,00307 & 0,00482 & 0,06939 & 0,04431 & 22,56818 \\
\hline $\begin{array}{l}\text { S\&P Lima General } \\
\text { (SPBLPGPT)Peru }\end{array}$ & 0,00350 & 0,00465 & 0,06821 & 0,05131 & 19,49055 \\
\hline BIST 100 (XU100)Türkiye & 0,00745 & 0,00401 & 0,06332 & 0,11762 & 8,50191 \\
\hline Bovespa (BVSP)Brezilya & 0,00162 & 0,00354 & 0,05952 & 0,02717 & 36,80675 \\
\hline $\begin{array}{l}\text { Costa Rica Indice Accionario } \\
\text { (IACR)Kostarika }\end{array}$ & 0,01298 & 0,00313 & 0,05598 & 0,23189 & 4,31230 \\
\hline MICEX (MCX)rusya & 0,00663 & 0,00263 & 0,05128 & 0,12933 & 7,73205 \\
\hline Belex 15 (BELEX15)Sırbistan & 0,00168 & 0,00262 & 0,05121 & 0,03274 & 30,54480 \\
\hline BET (BETI)Romanya & 0,00599 & 0,00252 & 0,05020 & 0,11939 & 8,37575 \\
\hline $\begin{array}{l}\text { BSE SOFIX } \\
\text { (SOFIX)Bulgaristan } \\
\end{array}$ & 0,00497 & 0,00225 & 0,04744 & 0,10484 & 9,53830 \\
\hline SET Index (SETI)Tayland & 0,01076 & 0,00194 & 0,04405 & 0,24431 & 4,09308 \\
\hline $\begin{array}{l}\text { COLCAP } \\
(\text { COLCAP)Kolombiya } \\
\end{array}$ & 0,00083 & 0,00178 & 0,04218 & 0,01979 & 50,53403 \\
\hline Güney Afrika 40 (invsaf40) & 0,00850 & 0,00139 & 0,03723 & 0,22815 & 4,38301 \\
\hline IPC (MXX)Meksika & 0,00569 & 0,00098 & 0,03127 & 0,18195 & 5,49588 \\
\hline BIRS (BIRS1)Bosna Hersek & $-0,00615$ & 0,00090 & 0,02993 & $-0,20555$ & $-4,86506$ \\
\hline $\begin{array}{l}\text { FTSE Malaysia KLCI } \\
\text { (KLSE)Malezya }\end{array}$ & 0,00370 & 0,00065 & 0,02546 & 0,14545 & 6,87519 \\
\hline $\begin{array}{l}\text { Amman Borsası } \\
\text { (AMGNRLX) Ürdüin }\end{array}$ & $-0,00153$ & 0,00063 & 0,02515 & $-0,06100$ & $-16,39460$ \\
\hline $\begin{array}{l}\text { BLOM STK IDX } \\
\text { (BLSI)Lübnan }\end{array}$ & $-0,00251$ & 0,00044 & 0,02091 & $-0,11985$ & $-8,34343$ \\
\hline
\end{tabular}

Tablo 2'de gelişmiş ülke endeksleri taşıdıkları risklere göre en yüksek riskten en düşük risk düzeyine göre sıralanmıştır. 
Tablo 2. Gelişmiş Ülkeler Risk Sıralaması

\begin{tabular}{|c|c|c|c|c|c|}
\hline Pazar Endeksleri & Ortalama & Varyans & $\begin{array}{c}\text { Standart } \\
\text { Sapma }\end{array}$ & Risk Primi & Değişim Katsayısı \\
\hline $\begin{array}{l}\text { Athens General } \\
\text { (ATG)Yunanistan } \\
\end{array}$ & $-0,00927$ & 0,00976 & 0,09880 & $-0,09380$ & $-10,66143$ \\
\hline FTSE MIB (FTMIB)İtalya & $-0,00003$ & 0,00379 & 0,06159 & $-0,00046$ & $-2194,77052$ \\
\hline IBEX 35 (IBEX)İspanya & $-0,00022$ & 0,00340 & 0,05828 & $-0,00370$ & $-269,97751$ \\
\hline $\begin{array}{l}\text { Budapest SE } \\
\text { (BUX)Macaristan }\end{array}$ & 0,00642 & 0,00337 & 0,05804 & 0,11062 & 9,04014 \\
\hline PSI 20 (PSI20)Portekiz & $-0,00534$ & 0,00286 & 0,05348 & $-0,09987$ & $-10,01257$ \\
\hline Nikkei 225 (N225)Japan & 0,00888 & 0,00281 & 0,05306 & 0,16731 & 5,97690 \\
\hline ATX (ATX)Avusturya & 0,00222 & 0,00273 & 0,05223 & 0,04257 & 23,48905 \\
\hline DAX (GDAXI)Almanya & 0,00988 & 0,00247 & 0,04969 & 0,19876 & 5,03128 \\
\hline $\begin{array}{l}\text { OMX Helsinki } \\
\text { (OMXHPI)Finlandiya }\end{array}$ & 0,00427 & 0,00218 & 0,04673 & 0,09144 & 10,93600 \\
\hline CAC AllShares (PAX)Fransa & 0,00498 & 0,00176 & 0,04200 & 0,11854 & 8,43605 \\
\hline $\begin{array}{l}\text { Oslo All Share } \\
\text { (OSEAX)Norveç }\end{array}$ & 0,00834 & 0,00157 & 0,03958 & 0,21078 & 4,74432 \\
\hline $\begin{array}{l}\text { OMX Iceland All-Share } \\
\text { (OMXIPI) İzlanda }\end{array}$ & 0,01194 & 0,00142 & 0,03762 & 0,31734 & 3,15117 \\
\hline $\begin{array}{l}\text { Taiwan Weighted } \\
\text { (TWII)Tayvan } \\
\end{array}$ & 0,00324 & 0,00141 & 0,03748 & 0,08649 & 11,56192 \\
\hline BEL 20 (BFX)Belçika & 0,00480 & 0,00133 & 0,03643 & 0,13167 & 7,59489 \\
\hline S\&P 500 (SPX)Amerika & 0,00964 & 0,00130 & 0,03603 & 0,26765 & 3,73617 \\
\hline $\begin{array}{l}\text { S\&P/ASX } 200 \\
\text { (AXJO)Avustralya }\end{array}$ & 0,00311 & 0,00128 & 0,03580 & 0,08696 & 11,50015 \\
\hline Tel Aviv 100 (TA100)İsrail & 0,00256 & 0,00126 & 0,03557 & 0,07204 & 13,88172 \\
\hline FTSE 100 (FTSE)İngiltere & 0,00433 & 0,001180 & 0,03435 & 0,1260394 & 7,93403 \\
\hline SMI (SSMI)İsviçre & 0,00355 & 0,001067 & 0,03266 & 0,1085776 & 9,21000 \\
\hline S\&P/TSX (GSPTSE)Canada & 0,00428 & 0,000744 & 0,02727 & 0,1567908 & 6,37792 \\
\hline
\end{tabular}

Tablo 2'den de görüldüğü gibi risk ölçütü olarak standart sapma değeri kullanılmıştır. Ülke endeksleri risk sıralamasında en yüksek risk taşıyan 3 ülke endeksi sırasıyla Yunanistan, İtalya ve İspanya olduğu tespit edilmiştir. Ayrıca gelişmiş ülke endeksleri içinde en az riskli olanları sırasıyla Kanada, İsviçre ve İngiltere olduğu anlaşılmaktadır.

Tablo 3'te gelişmiş ülke endekslerinden oluşturulan optimum portföy karması içinde yer alan ülkelerin, portföy içindeki ağırlıkları yer almaktadır. 
Tablo 3. Gelişmiş Ülkeler Optimum Portföy Karması

\begin{tabular}{|c|c|}
\hline OMX Iceland All-Share (OMXIPI) & 0,57 \\
\hline Nikkei 225 (N225)japan & 0,00 \\
\hline S\&P/TSX (GSPTSE)canada & 0,00 \\
\hline Budapest SE (BUX)macaristan & 0,00 \\
\hline Oslo All Share (OSEAX)norveç & 0,04 \\
\hline PSI 20 (PSI20)portekiz & 0,00 \\
\hline Taiwan Weighted (TWII)tayvan & 0,00 \\
\hline Athens General (ATG)yunanistan & 0,00 \\
\hline BEL 20 (BFX)belçika & 0,00 \\
\hline IBEX 35 (IBEX)ispanya & 0,00 \\
\hline Tel Aviv 100 (TA100)israil & 0,00 \\
\hline SMI (SSMI)isviçre & 0,00 \\
\hline CAC AllShares (PAX)fransa & 0,00 \\
\hline S\&P/ASX 200 (AXJO)avustralya & 0,00 \\
\hline ATX (ATX)avusturya & 0,00 \\
\hline FTSE 100 (FTSE)ingiltere & 0,00 \\
\hline OMX Helsinki (OMXHPI)finlandiya & 0,00 \\
\hline S\&P 500 (SPX)amerika & 0,38 \\
\hline DAX (GDAXI)almanya & 0,00 \\
\hline FTSE MIB (FTMIB)italya & 0,00 \\
\hline
\end{tabular}

Gelişmiş ülke endeksleri arasına yapılan kuadratik programlama sonucu oluşturulan optimum portföy karması Tablo 3'te gösterilmektedir. Optimum portföy karması Sharpe Oranını maksimum yapan portföy karmasını ifade etmektedir. Gelişmiş ülke endeksleriyle oluşturulan optimum portföyün Sharpe Oranı \% 0,36 çıkmış olup bu değer gelişmiş ülkelerde alınan 1 br.'lik riske karşılık günlük beklenen getiriyi ifade eder. Oluşturulan optimum portföy karması içinde İzlanda Pazar endeksinin \%57, Norveç'in \%4 ve Amerika'nın \%38 ağırlı̆a sahip olduğu anlaşılmıştır.

Tablo 4'te gelişmekte olan ülke endekslerinden oluşturulan optimum portföy karması içinde yer alan ülkelerin, portföy içindeki ağırlıkları yer almaktadır. 
Tablo 4. Gelişmekte Olan Ülkeler Optimum Portföy Karması

\begin{tabular}{|l|l|}
\hline Bursatil (IBC)venezuella & 0,12 \\
\hline BIST 100 (XU100)türkiye & 0,00 \\
\hline SET Index (SETI)tayland & 0,15 \\
\hline Belex 15 (BELEX15)sırbistan & 0,00 \\
\hline MICEX (MCX)rusya & 0,00 \\
\hline BET (BETI)romanya & 0,00 \\
\hline S\&P Lima General (SPBLPGPT)peru & 0,00 \\
\hline IPC (MXX)meksika & 0,06 \\
\hline FTSE Malaysia KLCI (KLSE)malezya & 0,14 \\
\hline BLOM STK IDX (BLSI)lübnan & 0,00 \\
\hline Costa Rica Indice Accionario (IACR)kostarika & 0,23 \\
\hline COLCAP (COLCAP)kolombiya & 0,00 \\
\hline Güney Afrika 40 (invsaf40) & 0,20 \\
\hline Shanghai Composite (SSEC)çin & 0,00 \\
\hline BSE SOFIX (SOFIX)bulgaristan & 0,00 \\
\hline Bovespa (BVSP)brezilya & 0,00 \\
\hline BIRS (BIRS1)bosnahersek & 0,00 \\
\hline Merval (MERV)arjantin & 0,09 \\
\hline KASE (KASE)kazakistan & 0,00 \\
\hline Amman Borsası (AMGNRLX)ürdün & 0,00 \\
\hline & \\
\hline
\end{tabular}

Gelişmekte olan ülke endeksleri arasına yapılan kuadratik programlama sonucu oluşturulan optimum portföy karması Tablo 4'te gösterilmektedir. Optimum portföy karması Sharpe Oranını maksimum yapan portföy karmasını ifade etmektedir. Gelişmiş ülke endeksleriyle oluşturulan optimum portföyün Sharpe Oranı \% 0,69 çıkmış olup bu değer gelişmekte olan ülkelerde alınan 1 br.'lik riske karşılık günlük beklenen getiriyi ifade eder. Oluşturulan optimum portföy karması içinde Venezuela Pazar endeksinin \%12, Tayland'ın \%15,Meksika'nın \%6 Malezya'nın \%14, Kosta Rika’nın \%23, Güney Afrika’nın \%20 ve Arjantin'in \%9 ağırlığa sahip olduğu anlaşılmıştır.

\section{Sonuç}

Çalışmada riski seven ve riskten kaçan yatırımcı tipleri için uygun optimum portföyler oluşturulmuştur. Oluşturulan portföylerle risk ve getiri beklentisi yüksek olan riski seven yatırımcı tipleri, risk ve beklenen getirisi düşük olan riskten kaçan yatırımcı tiplerini en faydalı pazarlara yönlendirmek amaçlanmıştır. Riski seven yatırımcı tipleri için gelişmekte olan piyasa endeksleri, riskten kaçan yatırımcı tipleri için ise gelişmiş piyasa endeks verileri kullanılmıştır. Yapılan analiz sonuçlarına göre riski seven yatırımcı tipleri için risk sıralamasında en yüksek risk taşıyan 3 ülke endeksi sırasıyla Venezuela, Arjantin ve Kazakistan olduğu tespit edilmiştir. En az riskli olanları sırasıyla Lübnan, Ürdün ve Bosna Hersek olduğu anlaşılmaktadır. Riskten 
kaçan yatırımcı tipleri için yapılan risk sıralamasında risk sıralamasında en yüksek risk taşıyan 3 ülke endeksi sırasıyla Yunanistan, İtalya ve İspanya olduğu tespit edilmiştir. En az riskli olanları sırasıyla Kanada, İsviçre ve İngiltere olduğu anlaşılmaktadır. Bu bilgiler doğrultusunda riski seven ve riskten kaçan yatırımcıların kendilerine uygun en yüksek fayda değerine ulaşabilmesi için, portföy içerisine dahil edecekleri endeksleri belirlerken risk düzeylerine uygun olan ülkelere yönelmeleri rasyonel olacaktır. Ayrıca gelişmiş ve gelişmekte olan ülke Pazar endeksleriyle oluşturulan optimum portföy karmalarına göre en yüksek Sharpe Oranını veren portföy karmaları oluşturulmuştur. Gelişmekte olan ülke endeksleriyle oluşturulan optimum portföyün Sharpe Oranı \% 0,69 çımış olup bu değer gelişmekte olan ülkelerde alınan 1 br.'lik riske karşılık günlük beklenen getiriyi ifade eder. Oluşturulan optimum portföy karması içinde Venezuela Pazar endeksinin \%12, Tayland'ın \%15,Meksika'nın \%6 Malezya'nın \%14, Kosta Rika'nın \%23, Güney Afrika'nın \%20 ve Arjantin'in \%9 ağırlığa sahip olduğu anlaşılmıştır. Gelişmiş ülke endeksleriyle oluşturulan optimum portföyün Sharpe Oranı \% 0,36 çıkmış olup bu değer gelişmiş ülkelerde alınan 1 br.'lik riske karşılık günlük beklenen getiriyi ifade eder. Oluşturulan optimum portföy karması içinde İzlanda Pazar endeksinin \%57, Norveç'in \%4 ve Amerika'nın \%38 ağırlığa sahip olduğu anlaşılmıştır. Bu bilgiler doğrultusunda riski seven ve riskten kaçan yatırımcıların en yüksek faydayı elde etmek için gelişmiş ve gelişmekte olan piyasalarda oluşturacakları portföy karmalarında ülke endeks ağırlıklarını göz önüne almaları önerilmektedir. Bundan sonra yapılacak akademik çalışmalara portföy optimizasyonlarının yatırımcı risk gruplarını dikkate alınarak gerçekleştirilmesi önerilmektedir. Ayrıca çalışmamız gelişmiş ve gelişmekte olan ülke grupları dikkate alınarak ele alınmış olup sonraki çalışmalar gelişmemiş ülke sınıfında yer alan ülkeleri de kapsayacak şekilde genişletilebilir.

\section{Kaynakça}

Akbulut, R., Kaderli, Y. (2009). Şanlıurfa il Merkezindeki Borsa Yatırımcılarının Profili ve Bu Yatırımcıların Hisse Senetlerine Yatırım Yapma Sürecini Etkileyen Faktörlerin Analizi. Muhasebe ve Finansman Dergisi, 43, 212-226.

Akçayır, Ö., Doğan, B., Demir, Y. (2014). Elton-Gruber Kısıtlı Markowitz Kuadratik Programlama Modeli ile Portföy Optimizasyonu: BIST-50 Üzerine Bir Uygulama. Süleyman Demirel Üniversitesi İktisadi ve İdari Bilimler Fakültesi Dergisi, 19 (3), 333-352.

Akman, M.O. (2011). Hisse Senedi Çeşitlendirmesi Yoluyla Optimum Portföy Oluşturma ve IMKK Uygulaması. (Yüksek Lisans Tezi). Balıkesir Üniversitesi Sosyal Bilimler Enstitüsü, Balıkesir.

Atan, M., Atan, S., Halıcı, B. (2018). Portföy Seçim Problemi Üzerine Karşılaştırmalı Alternatif Yaklaşımlar. Anadolu İktisat ve İşletme Dergisi, 2 (1), 24-37. 
Ayaydın, H. (2014). Uluslararası Çeşitlendirme, Finansal Bulaşma Ve Küresel Finansal Kriz İlişkisi Üzerine Bir Çalışma. Atatürk Üniversitesi İktisadi ve İdari Bilimler Dergisi, 28 (3), 43-67.

Aygören, H., Akyer, H. (2013). Etkin Portföylerin Belirlenmesinde Veri-Aralığı, Hisse Senedi Sayısı ve Risk Düzeyi Faktörlerinin Etkisi. Uluslararası Alanya İşletme Fakültesi Dergisi, 5 (2), 9-17.

Boztosun, D., Yalçiner, K., Atan, M. (2005). Karesel Programlama Yönteminin İmkb 100 Endeksine Uygulanması Ve Portföy Optimizasyonu. İktisat İsletme ve Finans, 20 (232), 70-83.

Cansın, K., Kocadağlı, O. (2012). Etkin sınır ve beta katsayı kısıtlı portföy seçim modeli üzerine bir uygulama. İstanbul Ticaret Üniversitesi Fen Bilimleri Dergisi, 11 (22), 19-35.

Çetin, A.C. (2007). Markowitz kuadratik programlama ile optimal portföy seçimi. Süleyman Demirel Üniversitesi İktisadi ve İdari Bilimler Fakültesi Dergisi, 12 (1), 63-81.

Ceylan, A., Korkmaz, T. (2004). Sermaye Piyasası ve Menkul Değer Analizi. İstanbul: Ekin.

Demirtaş, Ö., Güngör, Z. (2004). Portföy yönetimi ve portföy seçimine yönelik uygulama. Journal of Aeronautics and Space Technologies, 1 (4), 103-109.

Dünya Bankası, http://www.worldbank.org/en/country/mic/overview, (Erişim Tarihi 01.02.2018).

Francis, J.C. (1991). Investments. New York: McGraw-Hill International Editions.

Investing, https://tr.investing.com, (Erişim Tarihi 01.02.2018).

Karan, M.B. (2013). Yatırım Analizi ve Portföy Yönetimi. Ankara: Gazi.

Kardiyen, F. (2008). Portföy optimizasyonunda Ortalama mutlak sapma modeli ve Markowitz modelinin kullanımı ve İMKB verilerine uygulanması. Süleyman Demirel Üniversitesi İktisadi ve İdari Bilimler Fakültesi Dergisi, 13 (2), 335-350.

Keskintürk, T. (2007). Portföy Seçiminde Markowitz Modeli İçin Yeni Bir Genetik Algoritma Yaklaşımı. Yönetim, 18 (56), 78-90.

Korkmaz, T., Aydın, N. Sayılgan, G. (2013). Portföy Yönetimi. Eskişehir: Anadolu Üniversitesi.

Küçükkocaoğlu, G. (2002). Optimal Portföyün Seçimi ve İMKB Ulusal-30 Endeksi Üzerine Bir Uygulama. Active-Bankacılık ve Finans Dergisi, 26, 74-91.

Markowitz, H. (1952). Portfolio Selection. The Journal of Finance, 7 (1), 77-91. Doi: 10.1111/j.1540-6261.1952.tb01525.x.

Ramazan, A. (2013). Markowitz Karesel Programlama İle Portföy Seçimi: İMKB 30 Endeksinde Riskli Portföylerin Seçimi. Çukurova Üniversitesi Sosyal Bilimler Enstitüsü Dergisi, 22 (2), 175-194. 
Redman, A.L., Gullett, N.S., Manakyan, H. (2000). The performance of global and international mutual funds. Journal of Financial and Strategic Decisions, 13 (1), 75-85.

Sharpe, F.W. (1963). A Simplified Model For Portfolio Analysis. Management Science, 9 (2), 277-293. Doi: 10.1287/mnsc.9.2.277.

Tosun, Ö., Oruç, E. (2010). Portföy Büyüklüğünün Portföy Riski Üzerine Etkileri: İMKB-30 Üzerinde Test Edilmesi. Suleyman Demirel University the Journal of Faculty of Economics and Administrative Sciences, 15 (2), 479-493. 